\title{
Area Suitability Prediction for Conserving Elephants: An Application of Likelihood Ratio Prediction Model
}

\author{
M.S.L.R.P. Marasinghe ${ }^{*}$, N.D.K. Dayawansa ${ }^{1}$ and R. P. De Silva ${ }^{1}$ \\ Postgraduate Institute of Agriculture \\ University of Peradeniya \\ Sri Lanka
}

\begin{abstract}
Asian elephant (Elephas maximus) is the largest terrestrial mega herbivore in Asia. Their distribution is highly fragmented and occurs only in thirteen countries in the world. Survival of the Asian elephant is endangered mainly due to the habitat loss. Implementation of development projects in areas where elephants are habitually present is a challenge and rational location of the development projects avoiding elephant habitats requires considerable amount of resources and time. Therefore, development of a cost effective methodology for evaluating the existing and potential elephant habitats is a necessity. Ecological factors affecting elephant behaviour are spatial in nature. Use of the likelihood ratio model with geo-informatics enables evaluation of the effects of spatial factors and their interrelations on occurrence of a certain event or a phenomenon. The objective of this study was to employ Geographic Information System (GIS) and Remote Sensing techniques in evaluating the suitability of a given area for elephants using likelihood ratio prediction model. The study was carried out in the north-western and Mahaweli wildlife region of the Department of Wildlife Conservation using two elephant herds. The percentage slope, Normalized Difference Vegetation Index (NDVI), Normalized Difference Water Index (NDWI) and Normalized Difference Built-up Index (NDBI) were used to reflect the factors such as terrain, food and water availability and manmade disturbances, which influence on the habitat preference of elephants. The predicted elephant preference area map was compared and accuracy was tested with the actual preference area map developed using the telemetry data on movement of the two herds. It was found that the likelihood ratio prediction model could be used in predicting area suitability of elephants with $79 \%$ accuracy. As the prediction shows an acceptable level of accuracy, the model could be used in practical decision making and investment planning. This model could be further improved by including variables that represents manmade disturbances more effectively.
\end{abstract}

Keywords: Habitat preference modelling, human-elephant conflict, likelihood ratio, spatial modelling

\section{INTRODUCTION}

Asian elephant (Elephas maximus) is the largest terrestrial megaherbivore in Asia (Santiapillai \& De Silva, 1994). Its distribution is highly fragmented and occurs only in thirteen countries in Asia, i.e. India, Sri Lanka, Nepal, Bhutan, Bangladesh, Myanmar, China, Thailand, Laos, Cambodia, Vietnam, Malaysia and Indonesia (Kemf \& Santiapillai,

\footnotetext{
1 Department of Agricultural Engineering, Faculty of Agriculture, University of Peradeniya, Sri Lanka

Corresponding author: ranjandwc@ gmail.com
} 
2000). In the present context, survival of the Asian elephant is endangered by habitat loss and conflict with humans over crop raiding (Sukumar 1989, De Silva 1998, Santiapillai \& Jackson 1990, Corea, 2006).

According to the finding of the 2012 Elephant Survey, more than 5,879 wild elephants exist in Sri Lanka (Department of Wildlife Conservation, 2012). However when considering the human population, Sri Lanka is one of the most densely populated countries (United Nations, 2008). The ever growing complex human needs create a greater demand for mega development projects that open up elephant habitats to human use (Marasinghe, et al., 2012). It is a known fact that, the fragmentation and loss of the natural habitats of elephants (Desai, 1998) are considered to be the main cause of Human Elephant Conflict in Sri Lanka (Bandara, 2005). If the existing trend of habitat loss is continued, elephant is on the fast track to extinction (Santiapillai \& De. Silva, 1994).

Implementation of development project, in areas where elephants are habitually present is a greater concern in today's context (Marasinghe et al., 2012). The major difficulty faced by the decision makers is rational location of the infrastructure projects avoiding elephant habitats or with minimal disturbance to the existing elephant ranging areas (Marasinghe et al., 2012). Often areas set aside for elephants considering the forest cover only were not preferred by elephants and elephants tend to move in to unexpected areas making the situation more complex. Identification of elephant ranging areas and areas suitable for conservation as elephant habitats is often required in Environment Impact Assessments (EIA) of development projects for sticking a balance between development and elephant conservation. Such studies are time and resource consuming as they require greater effort on field level data collection. However, it is not advisable to depend on previously collected data as a measure of cutting down costs, as manmade factors such as habitat fragmentation due to development and natural factors such as climatic change tend to vary the elephant ranging areas. Hence it is a necessary requirement for conservators, resource managers and project planers to find out a quick, low cost, yet precise technique for generating existing elephant ranging areas that need to be avoided as far as possible and find out suitable areas which need to be conserved for elephants. With the contemporary emphasis on "Managed Elephant Reserves" as a mechanism for addressing the Human Elephant Conflict issues, rational determination of the suitability of a potential conservation area is an essential requirement prior to investment. As investment on "Managed Elephant Reserves" is colossal, wrong decisions may result greater losses to the economy and further aggravate the problems (DWC, 2010; 2011). Geo-informatics and Remote Sensing is a widely used cost effective tool that could be employed in generating decision supporting data and information in larger geographic areas. Hence, it could be used in finding out a solution to this problem.

Movement of elephants and their likes and dislikes towards a given area is linked with landscape, and topography (Wall et al., 2006). Surface water availability is the best predictor of seasonal range used by elephants (Smith et al., 2007, Harris et al., 2008 and Cushman et al., 2010, Hoare, 1999). The ecological factors such as land cover and topographical factors such as slope are the variables that best represent the elephant distribution (Dimer, 2003) in a given locality. Since those ecological factors are spatial in nature, Geo-informatics could be used in indentifying the relationship between such factors and their relative contribution on elephant behaviour. 


\section{Objectives}

This study was conducted with the following objectives.

- to employ Geo-informatics and Remote Sensing techniques in identifying the relative importance of ecological and geographical factors that contribute to habitat preference of elephants.

- to develop a model to predict the potential areas that could be managed as elephant reserves.

\section{METHODOLOGY}

The study was carried out in North-Western and Mahaweli Wildlife Region of the Department of Wildlife Conservation (Fig.1). The study is based on two elephant herds roaming in two locations. First herd was roaming in Kekirawa, and Kebitigollewa Divisional Secretariat Divisions (Fig. 2) and the second heard was roaming in Giribawa, Galgamuwa, Ambanpola, Kotawehera and Rasnayakapura Divisional Secretariat Divisions (Fig. 3).
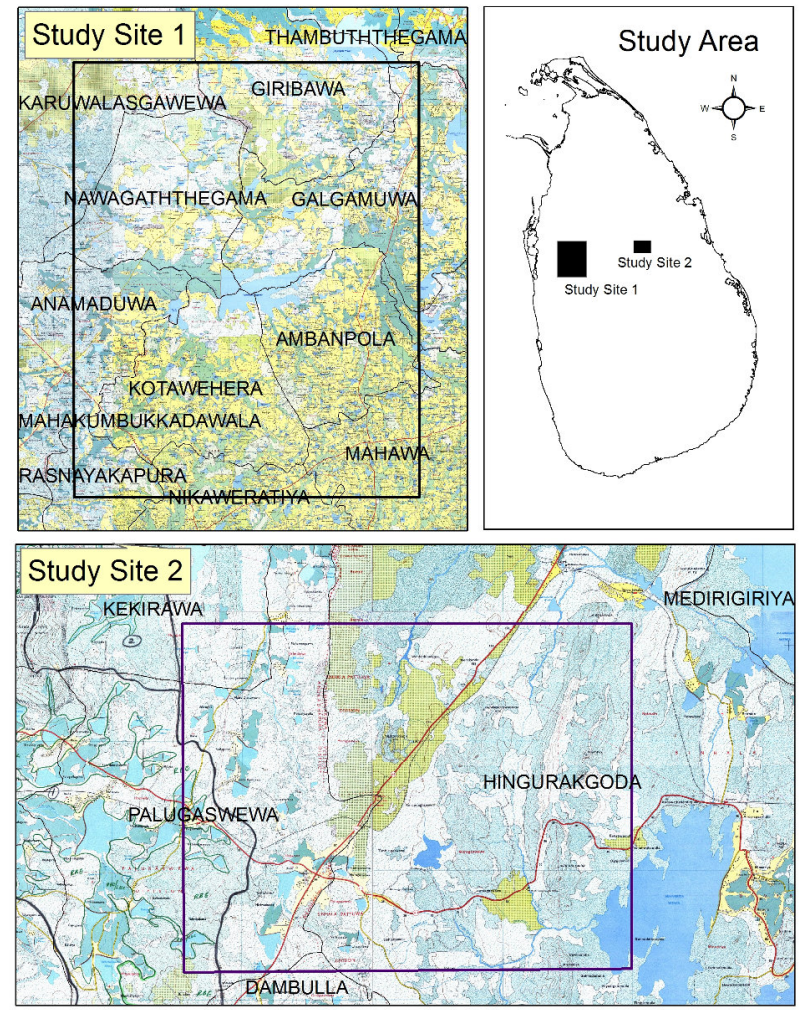

Fig. 1. The study area 
Using telemetry data on elephant movements, spatial preference maps for two elephant herds were developed. The areas where elephants spent more time were marked as preferred areas and rest of the landscape is marked as less preferred areas. The maps were prepared with the location details of the herds recorded in 8 hour intervals from September 2009 to May 2010 by calculating the kernel densities.

Elephants' preference towards a given areas depends on factors such as terrain, food and water availability and manmade disturbances (Marasinghe et al., 2012). Hence, percentage slope, Normalized Difference Vegetation Index (NDVI), Normalized Difference Water Index (NDWI) and Normalized Difference Built-up Index (NDBI) were used in order to reflect those factors. NDVI reflects the fodder availability while NDWI reflects the water availability in different levels. NDBI reflects man made disturbance. Each factor was classified in to factor classes (NDVI class1, NDVI Class 2 etc.) and likelihood ratios of elephant presence and absence was calculated for each factor class in the site 1 and using those values preferred and less preferred areas of elephants were predicted for the site 2 using likelihood ratio prediction model. The predicted elephant preference map was compared and accuracy was tested with the actual preference map developed using the telemetry data.

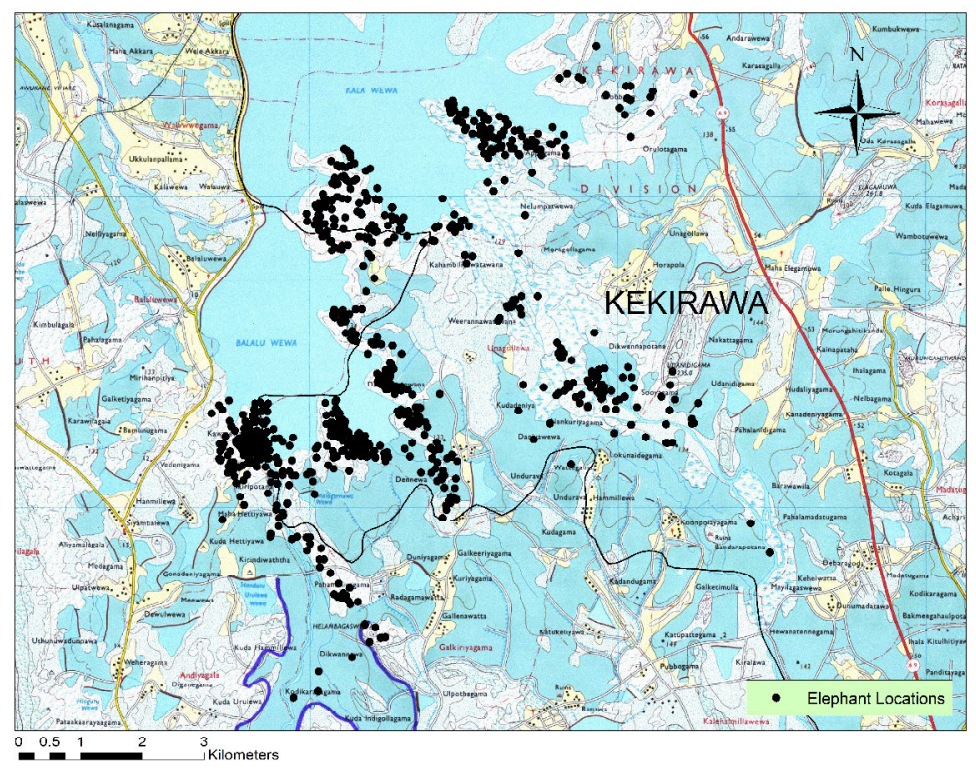

Fig. 2. Elephant Locations in Site 1

\section{Likelihood Ratio Model}


The likelihood ratio prediction model is a technique used in solving the prediction problems in wider spectrum of disciplines. It has been applied to quantify medical diagnoses from clinical symptoms to predict diseases (Spiegelhalter \& Knill-Jones, 1984) and in geology, likelihood ratio prediction model has been used to search the potential mineral deposit area (Reboh, \& Reiter, 1983). Reddy et al. (1992) applied the same approach to the prediction of base-metal deposits in a greenstone belt. Likelihood ratio prediction model was also used in ecological GIS applications (Aspinall, 1992).

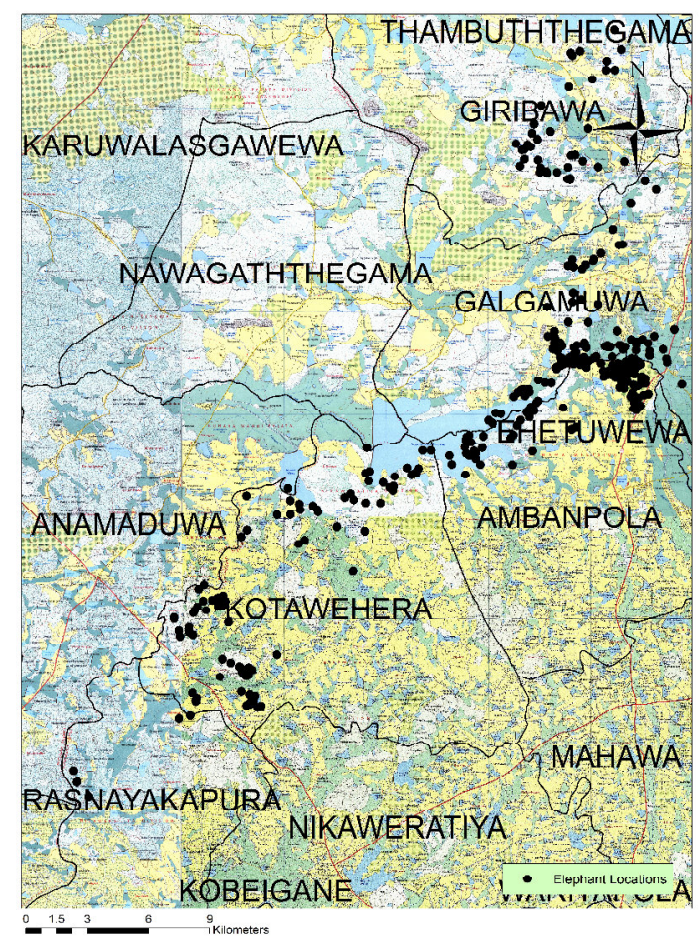

Fig. 2. Elephant locations in Site 2

In this study, likelihood ratio prediction model is described in the context of mapping areas that are preferred by the elephants. The likelihood ratio represents the ratio of the two spatial distribution functions, those preferred by the elephants and those less preferred by the elephants. Fig. 4 shows the conceptual explanation of the likelihood ratio prediction model. It was assumed that the spatial distribution functions of the areas preferred by elephants and those not preferred by elephants are distinctly different. 
For example, LR (AlE), the likelihood ratio of the elephant preference at factor type A in Fig. 4 is;

$$
L R(A \backslash E)=\frac{P(A \backslash E)}{P(A \backslash \bar{E})}
$$

Where $\mathrm{P}(\mathrm{AlE})$ is the conditional probability of factor type A given the Elephant Preferred Area and $\mathrm{P}(\mathrm{A} \backslash \tilde{E})$ is the conditional probability of factor type A given the absence of preferred Area. Hence;

and

$$
P(A \backslash E)=\frac{P(E \cap A)}{P(E)}=\frac{N[X] / N[S]}{N[E] / N[S]}=\frac{N[X]}{N[E]}
$$

$$
\mathrm{P}(\mathrm{A} \backslash \bar{E})=\frac{P(\bar{E} \cap A)}{\mathrm{P}(\bar{E})}=\frac{(N[A]-N[X]) / N[S]}{(N[S]-N[E]) / N[S]}=\frac{N[A]-N[X]}{N[S]-N[E]}
$$

Therefore;

$$
\begin{array}{rlr}
\operatorname{LR}(\mathrm{A} \backslash \mathrm{E}) & =\frac{N[X]}{\mathrm{N}[\mathrm{E}]} \div \frac{(N[A]-N[X])}{(N[S]-N[E])} & \\
& =\frac{N[X] \cdot(N[S]-N[E])}{N[E] \cdot(N[A]-N[X])} & \frac{A]-N[X])}{S]-N[E])}
\end{array}
$$

Where;

$\mathrm{N}[\mathrm{S}]=$ Total no. of Pixels in the land area $\mathrm{N}[\mathrm{A}]=$ Total no. of Pixels in the area covered by Factor Class A $\mathrm{N}[\mathrm{E}]=$ Total no. of Pixels in the Elephant Preferred Area $\mathrm{N}[\mathrm{X}]=$ Pixels in Elephant Preferred area fallen inside Factor Class A 


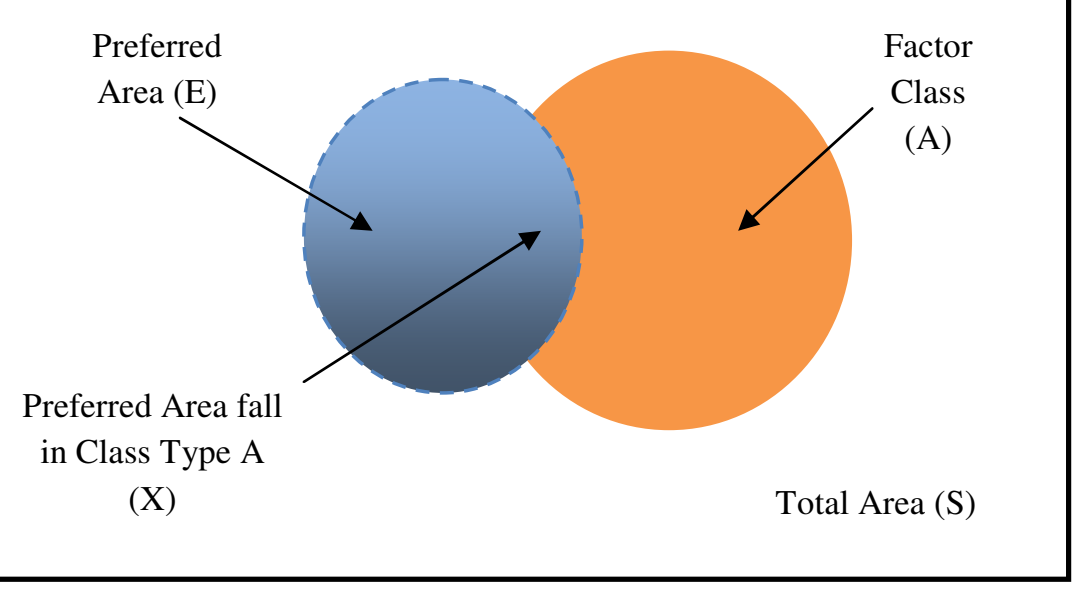

\section{Fig. 4. Explanation of Likelihood Ratio Prediction Model}

If the value of Likelihood Ratio is greater than 1, then the presence of factor class A, is an important positive evidence for habitat preference by elephants. However, if the pattern is negatively correlated with the habitat preference, Likelihood Ratio would be less than 1 . If the pattern is uncorrelated with the habitat preference, then Likelihood Ratio becomes 1 .

Thus, for each factor class in site 1, areas preferred by elephants and less preferred areas were initially computed. Preference of the areas was computed based on the frequency of visit to an area using the telemetry data. The likelihood ratio function for the factor class layers of site 1 was computed. Bayesian combination rule was used in combining the likelihood ratio functions (Equation 6) for all factor classes (Han, 2003) and the predicted elephant preference (EP) map was generated from these combined likelihood ratio value. The model was validated using the data from site 2 .

$$
E P_{i}=\prod_{j=1}^{m} L R \cdot V_{j}(p)
$$

Where:

$$
\begin{array}{ll}
\mathrm{LR} & =\text { Likelihood Ratio and } \\
\mathrm{V}_{\mathrm{j}}(\mathrm{p}) & =\text { point value of the } \mathrm{j}^{\text {th }} \text { feature class raster (e.g. NDVI Class } 1 \\
& \text { pixel } 1 \text { etc.). }
\end{array}
$$

\section{Data and Data Sources}

Spatial preference of the elephants were generated from the telemetry data of the Department of Wildlife Conservation and percentage slope was derived from elevation data from the 1:50000 scale topographic maps of Sri Lanka The NDVI, NDWI and NDBI were generated from the multispectral data of IRS LISS III sensor obtained in year 2010 (Table 1). The NDVI, NDWI and NDBI were used in order to represent the food, water and manmade disturbance as the land use maps were not up-to-date and hence do not accurately reflect the characters of the study sites existed at the time of telemetry data collection. As elephant is a 
large animal and consumes a large home range, all the data layers were converted to $1 \mathrm{kmX} 1$ $\mathrm{km}$ pixels prior to analysis as using fine pixel sizes were meaningless. The conceptual framework of the methodology that shows the usage of data is shown in Fig. 5.

Table 1. Spatial Data used in the study

\begin{tabular}{lll}
\hline \multicolumn{1}{c}{ Data Layer Name } & \multicolumn{1}{c}{ Source } & \multicolumn{1}{c}{ Representing Factor } \\
\hline Elephant Preferred Area & Telemetry Data & Spatial loyalty \\
Percentage Slope & 1:50000 maps & Terrain Features \\
NDVI & IRS LISS III & Food Availability \\
NDWI & IRS LISS III & Water availability \\
NDBI & IRS LISS III & Human Activities \\
\hline
\end{tabular}

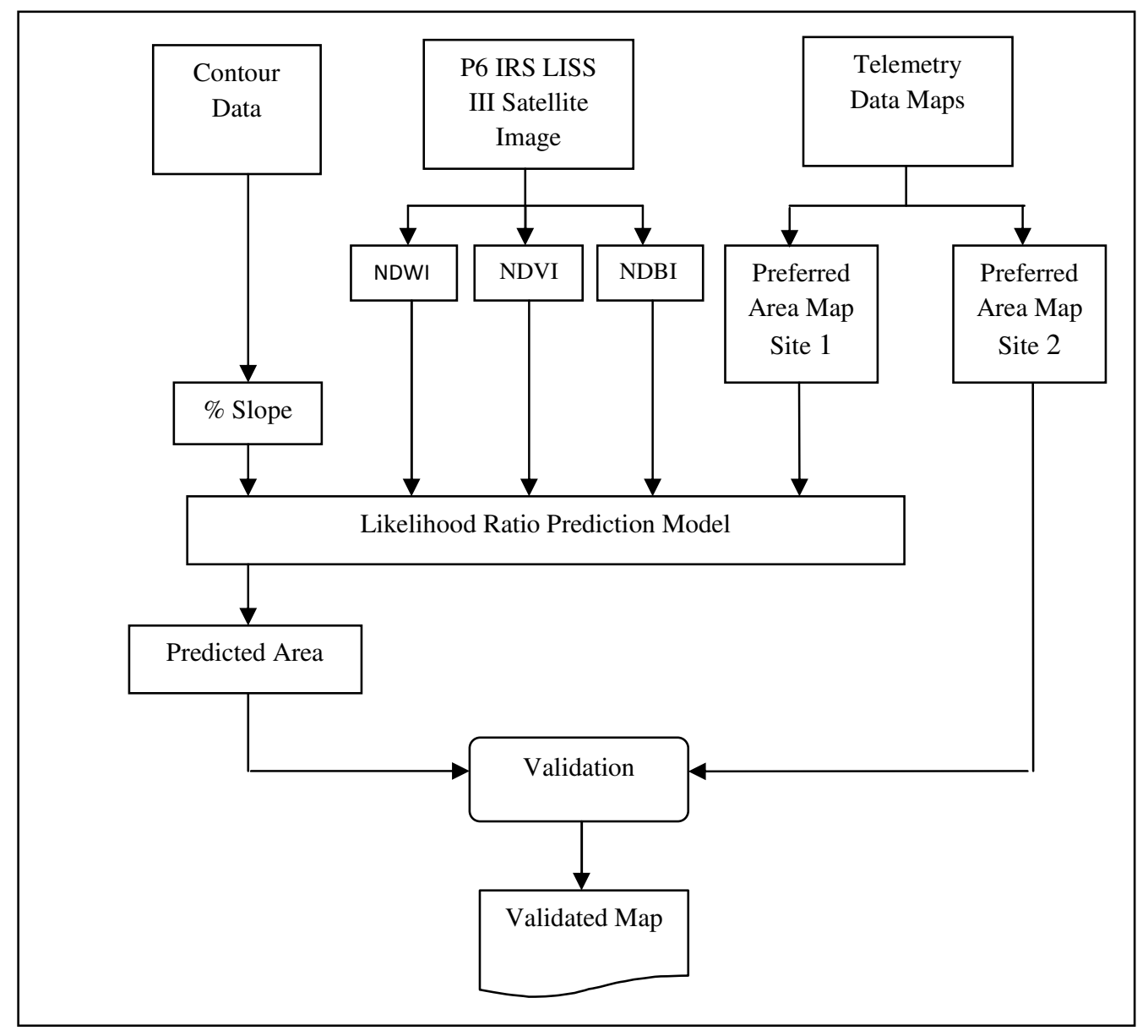

Fig. 5. Conceptual Framework of the Methodology 
The Normalized Difference Water Index (NDWI) was derived in order to identify the water features. The outcomes of this equation are water features that have positive values whilst soil and terrestrial vegetation have zero or negative values (McFeeters, 1996). The normalized difference water index (NDWI) was derived using the same principles of the Normalised Difference Vegetation Index (NDVI). NDVI index is calculated as follows;

$$
N D V I=\frac{(N I R-R e d)}{(N I R+R e d)}
$$

NIR denotes Near Infrared band. If the Green band and the NIR band are used instead of the NIR and Red, then the outcome would be reversed and the vegetation suppressed and the open water features will be enhanced (McFeeters, 1996). Hence equation for an NDWI is;

$$
N D W I=\frac{(\text { Green }-N I R)}{(\text { Green }+N I R)}
$$

In order to identify the built up areas, Zha et al. (2003) proposed a similar methodology. In this approach, first NDVI and Normalized Difference Built up Index (NDBI) were derived. The NDBI could be calculated using following equation.

$$
N D B I=\frac{(S W I R-N I R)}{(S W I R-N I R)}
$$

\section{RESULTS AND DISCUSSION}

Except the elephant preferred and less preferred raster layer, other raster data layers were reclassified into 5 classes. In re-classifying, first the raster layers for the site 1 were classified using equal intervals and the class intervals were recorded. Then the layers for site 2 were classified using the class intervals used in the site 1 data layers. The class 1 represents the lower value of the feature and the class 5 represents the highest value (e.g. class 1 of the slope layer is the least slopy areas and class 5 is the highest slopy areas).

Home range boundary of the $1^{\text {st }}$ herd was used to extract DEM, Slope, NDVI, NDWI and NDBI for the home range. The likelihood ratios were calculated for the site 1 using generated factor class layers and the elephant present-absent map. The calculated Likelihood values are shown in Table 2. 
The derived likelihood ratio values were used in predicting the areas (Equation 6) that was expected to be preferred by the elephants. In data analysis and preparation, Arc GIS software was used and the final model was established using ERDAS Imagine.

The forecast was done for the entire area which is the minimum bounding envelop of the home range of the second herd (Site 2). The forecasted area raster is shown in Fig. 6. Light colour areas are the expected preferred areas for elephants and dark colour areas are the expected less-preferred areas.

The home range of the elephant herd in site 2 is about $432 \mathrm{~km}^{2}$ and out of the total 381 elephant locations in the telemetry dataset 81 points were located in predicted less preferred areas and 300 points were located in predicted preferred areas $(78.74 \%)$.

Table 2. Likelihood Ratio Calculations

\begin{tabular}{lrrrrrc}
\hline \multicolumn{1}{c}{ Layer } & Class & $\mathbf{N}[\mathbf{A}]$ & $\mathbf{N}[\mathbf{X}]$ & $\mathbf{N}[\mathbf{E}]$ & $\mathbf{N}[\mathbf{S}]$ & $\mathbf{L R}$ \\
\hline \%Slope & 1 & 90 & 30 & 49 & 140 & 0.928571 \\
& 2 & 17 & 8 & 49 & 140 & 1.650794 \\
& 3 & 14 & 7 & 49 & 140 & 1.857143 \\
& 4 & 7 & 3 & 49 & 140 & 1.392857 \\
NDWI & 5 & 12 & 1 & 49 & 140 & 0.168831 \\
& 1 & 121 & 47 & 49 & 140 & 1.179537 \\
& 2 & 8 & 2 & 49 & 140 & 0.619048 \\
& 3 & 1 & 0 & 49 & 140 & 0.000000 \\
NDVI & 4 & 0 & 0 & 49 & 140 & 0.000000 \\
& 5 & 10 & 0 & 49 & 140 & 0.000000 \\
& 1 & 2 & 0 & 49 & 140 & 0.000000 \\
& 2 & 4 & 2 & 49 & 140 & 1.857143 \\
NDBI & 3 & 23 & 7 & 49 & 140 & 0.812500 \\
& 4 & 82 & 33 & 49 & 140 & 1.250729 \\
& 5 & 29 & 7 & 49 & 140 & 0.590909 \\
& 1 & 117 & 43 & 49 & 140 & 1.079151 \\
& 2 & 13 & 6 & 49 & 140 & 1.591837 \\
& 3 & 0 & 0 & 49 & 140 & 0.000000 \\
& 4 & 0 & 0 & 49 & 140 & 0.000000 \\
& 5 & 10 & 0 & 49 & 140 & 0.000000 \\
\hline
\end{tabular}

\section{CONCLUSIONS}

According to the results of the study, it was shown that the likelihood ratio prediction model could be used in predicting areas suitable for elephants. Out of the total locations $78.74 \%$ of the locations were accurately identified as preferred areas for elephants. It was also found that the Percentage Slope, Normalized Difference Vegetation Index (NDVI), Normalized Difference Water Index (NDWI) and Normalized Difference Built-up index (NDBI) could be 
effectively used in the model. As the prediction could be done with $78.74 \%$ accuracy, the model could be used practically in management decision making and investment planning. In the model estimation and simulation, ecological and topographical variables (NDVI, NDWI, and Percentage Slope) were used compared to variables reflecting manmade disturbances (NDBI). Hence it could be suggested that the model could be further improved by including variables that represents manmade disturbances and also provide weights based on their relative importance.

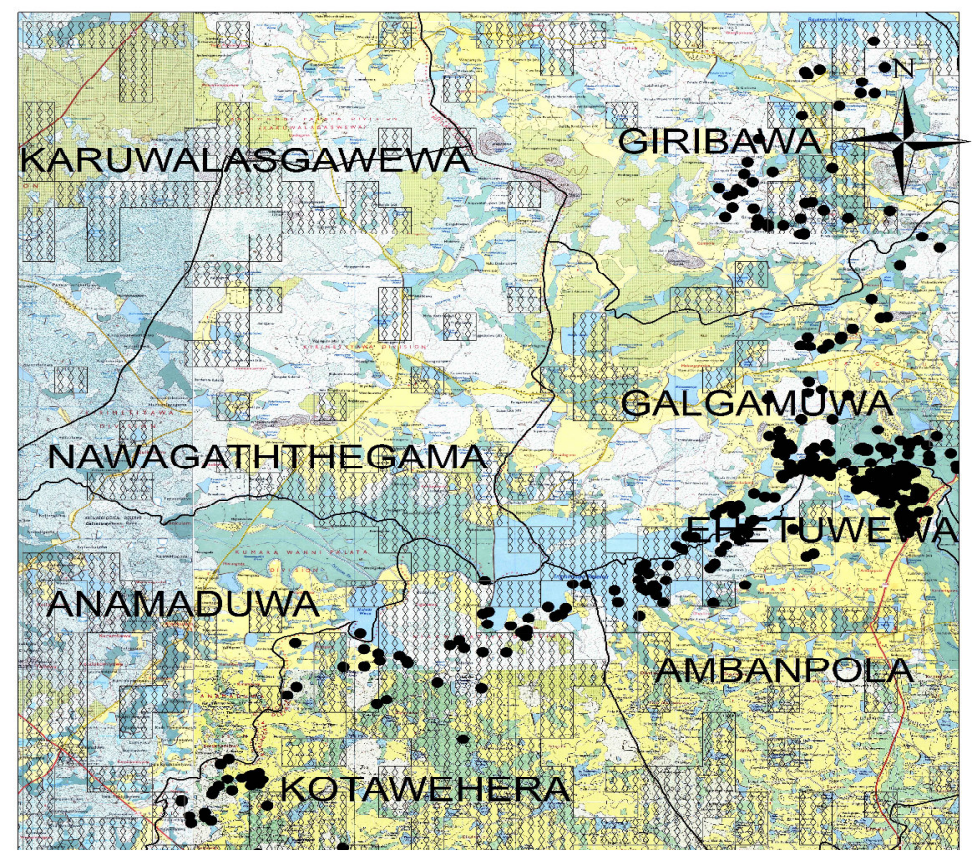

Fig.6. Forecasted Elephant Preference Map

\section{ACKNOWLEDGEMENT}

The authors would like to acknowledge the financial support provided by the National Research Council of Sri Lanka through grant No. 12-098 to carry out this study. The 
telemetry data and other assistance provided by the Department of Wildlife Conservation and its staff are also greatly appreciated.

\section{REFERENCES}

Aspinall, R.J. (1992). An inductive modeling procedure based on Bayes' theorem for analysis of pattern in spatial data: International Journal of Geographical Information System. 6(2), 105-121.

Bandara, R. (2005). The Economics of Human-Elephant Conflict, Ministry of Environment and Natural Resources, Colombo, Sri Lanka, pp 3-5.

Corea, R. (2006). Establishing a sustainable model for long-term conservation of the elephant in Sri Lanka. Gajah. 24, 13-17.

Cushman, S.A., Chase M.J., and Griffin. C. (2010). Mapping Landscape resistance to identify corridors and barriers for elephant movement in southern Africa. In S.A. Cushman and F. Huettmann (Ed.), Spatial Complexity, Informatics, and Wildlife Conservation, (pp. 349-367). Springer, Japan.

De Silva, M. (1998). Status and conservation of the elephant (Elephas maximus) and the alleviation of man-elephant conflict in Sri Lanka. Gajah. 19, 1-78.

Department of Wildlife Conservation (2012). First National Survey of Elephants in Sri Lanka, Unpublished Survey Report, Colombo, Sri Lanka.

Desi, A.A. (1998). The Conservation of Elephants and Human-Elephant Conflict in Sri Lanka (Unpublished Technical Report), Department of Wildlife Conservation, Colombo, Sri Lanka.

Diemer, N. (2003). Environmental Suitability Analysis for Asian Elephants in Southern India, Unpublished MSc Thesis, International Institute of Geo-information Science and Earth Observation, Enschede, The Netherlands.

DWC (2010, 2011). Progress Reports of the Department of Wildlife Conservation, (unpublished), Colombo.

Han J.G., Ryu H.K., Chi, K.H., and Yeon, Y.K. (2003), Published in proceedings APWeb, 03, Proceedings of the $5^{\text {th }}$ Asia-Pacific Web Conference on Web-technologies and Applications, Springer-verlag, Berlin, Heidelberg, ISBN 3-540-02354-2, pp 370-381.

Harris, G.M., Russell, G.J., Van Aarde, R.I., Pimm, S.L. (2008). Rules of habitat use by elephants Loxodonta africana in southern Africa: Insights for regional management. Oryx, 42, 66-75.

Hoare, R.E. (1999). Determinants of human elephant conflict in a land-use mosaic. Journal of Applied Ecology. 36, 689-700. 
Kemf, E. and Santiapillai, C. (2000). Asian Elephants in the Wild: 2000 WWF Species Status Report, WWF-International, Gland, Switzerland.

Marasinghe, M.S.L.R.P., De Silva, R.P., and Dayawansa, N.D.K. (2012). Feasibility of Using Energy Cost Based Geo-Informatics Models for Decision Supporting in Infrastructure Development and Management Projects in Elephant Ranging Areas, pp 52- 57, In: Mehmood H., De Silva R.P., Tripathi, N.K., (Ed) Proceedings of $4^{\text {th }}$ International Conference on GeoInformation Technology for Natural Disaster Management, Geoinformatics International, Pathumthani, Thailand.

McFeeters S.K. (1996) The use of the Normalized Difference Water Index (NDWI) in the delineation of open water features. International Journal of Remote Sensing. 17(7), 14251432.

Reboh, R. and Reiter, J. (1983). A knowledge-based system for regional mineral resource assessment: Final report- Contract No 14-18-0001-20717, SRI project 4119, p 267.

Reddy R.K.T., Agterberg F.P., and Bonham-Carter G.F. (1992). Application of GIS-based logistic models to base-metal potential mapping in snow Lake area, Manitoba. Canadian Conference on GIS, Ottawa, Canada.

Santiapillai, C. and Jackson, P. (1990). The Asian elephant: an action plan for its conservation, IUCN/SSC Asian Elephant Specialist Group, IUCN, Gland, Switzerland.

Santiapillai, C., and De Silva. M. (1994). An Action Plan for the Conservation and Management of Elephant (Elephas maximus) in Sri Lanka. Gajah. 13, 1-24.

Smit, I.P.J., Grant, C.C. and Whyte, I.J. (2007). Landscape-scale segregation in the dry season distribution and resource utilization of elephants in Kruger National Park, South Africa. Diversity and Distributions. 13, 225-236.

Spiegelhalter, D.J. and Knill-Jones, R.P. (1984). Statistical and knowledge-based approaches to clinical decision-support systems, with an application in gastroenterology: Journal of the Royal Statistical Society. 1, 35-77.

Sukumar, R. (1989). The Asian elephant: ecology and management, Cambridge University Press, Cambridge.

United Nations (2008). Statistical Yearbook - Fifty-second issues, United Nations, New York, USA.

Wall, J., Douglas-Hamilton, I., and Vollrath, F. (2006). Elephants avoid costly mountaineering. Curr Biol. 16. 527-529.

Zha, Y.,Gao, Y. and Ni, S. (2003). Use of normalized difference built-up index in automatically mapping urban areas from TM imagery. International Journal of Remote Sensing. 24. 583-594. 